\title{
Fifteen proposals of demonyms for capitals of the European Union
}

\section{[Quince propuestas de gentilicios para capitales de la Unión Europea]}

\author{
Beatriz Gómez-Pablos
}

\section{DOI: $10.18355 /$ XL.2016.09.03.25-43}

\section{Resumen}

El tema de los gentilicios plantea numerosas cuestiones aun no resueltas. El problema principal dimana generalmente de los topónimos extranjeros en español. La RAE, la ASELE, los departamentos de traducción (ONU y UE), por un lado, y los manuales de estilo o los diccionario de dudas, por otro, proponen distintas soluciones. Esas propuestas carecen con frecuencia de criterios precisos y coherentes y son cada vez más las voces que exigen cierta homogeneidad a favor de la unidad de la lengua. Nuestro objetivo es analizar un pequeño campo para el que urge crear o reconocer de manera oficial algunos gentilicios.

Palabras clave: gentilicios, capitales europeas, lexicología, onomástica, norma y uso

\section{Introducción}

Sobre el tema de los gentilicios se ha escrito mucho en los últimos años, tanto en el ámbito internacional relacionado con organismos que cuentan con departamentos de traducción, como en el ámbito interno del mundo hispánico. A ambos niveles y desde ambas perspectivas se han llevado, y se llevan continuamente, a cabo diversas propuestas de topónimos extranjeros en español y también de sus respectivos gentilicios.

Entre las instituciones internacionales dedicadas a la tarea de normalizar topónimos y gentilicios destacan dos: la Organización de Naciones Unidas y la Oficina de Traductores de la Unión Europea ${ }^{1}$. Su motivación es puramente práctica, pues precisan de esos términos para los documentos oficiales. Sin ir más lejos, la Unión Europea trabaja con once idiomas a los que se vierten todos los protocolos, es decir, se trata de un esfuerzo lingüístico considerable. Ambos organismos tienen publicadas listas de topónimos y gentilicios que se pueden consultar en la red. Dichas listas, sin embargo, presentan ciertas disonancias, algunos nombres de países se recogen según el nombre oficial y otros según el nombre usual; pero también se aplican criterios fonéticos y gráficos diferentes. De ahí, que se requiera una institución superior en materia lingüística, y a la vez independiente desde el punto de vista político.

Junto a las dos organizaciones mencionadas, se hallan otras de carácter nacional. Son numerosos los países hispanohablantes que cuentan con institutos geográficos. Una sus principales tareas consiste en normalizar, recopilar y difundir la toponimia, así como en formar el nomenclátor geográfico nacional, un registro dinámico de información, que recoge las denominaciones que deben utilizarse en la cartografía oficial. No obstante, el objetivo de esos organismos se limita a normalizar topónimos del ámbito nacional y suelen excluirse los topónimos extranjeros.

Otro grupo lo componen las instituciones nacionales relacionadas de modo directo con la lengua, tanto a nivel oficial, la Real Academia Española y las Academias de la

\footnotetext{
${ }^{1}$ Obviamente existen otras muchas instituciones internacionales, ajenas a la política, que para su actividad necesitan conocer los topónimos y gentilicios. Así el Comité Internacional de la Cruz Roja, por ejemplo, cuenta con su propia lista de países.
} 
Lengua, como a nivel privado, las empresas de los medios de comunicación. En los últimos diez años, la RAE en colaboración con la Asociación de Academias de la Lengua ha publicado importantes obras: el Diccionario panhispánico de dudas (2005), la Ortografía (2010), la Nueva Gramática (2010), el manual de estilo El buen uso del español (2013) y la vigésimo tercera edición del Diccionario de la lengua española (2014). Todas ellas se complementan, incluso en lo que se refiere al tema de los topónimos y gentilicios.

Las empresas de los medios de comunicación, por su parte, desempeñan una doble función, pues contribuyen por un lado a la difusión de algunos términos y ejercen, en este caso, un papel determinante en materia lingüística, que no puede ser pasado por alto, ya que su influencia hace que se impongan determinados usos. Por otro lado, muchos de esos medios de comunicación, conscientes de la necesidad de disponer de herramientas de trabajo que faciliten la redacción de textos y que, al mismo tiempo, definan el estilo del medio en cuestión, elaboran manuales dirigidos a los propios empleados ${ }^{1}$. Esos manuales o libros de estilo confeccionados por especialistas ofrecen también información sobre topónimos y gentilicios. Sin embargo, acusan llamativas discordancias y serias lagunas.

Otra fuente importante en la actualidad es la Fundación del Español Urgente (Fundéu BBVA), nacida en 2005 como fruto de un acuerdo entre la Agencia Efe y el banco BBVA. Para esta institución su objetivo principal es impulsar el buen uso del español en los medios de comunicación. Además de ofrecer un servicio de consultas y recomendaciones y diversos cursos para profesionales, ha publicado varias ediciones de su conocido Manual de español urgente, punto de referencia para numerosos periodistas hispanohablantes. La Fundación Fundéu no goza solo de reconocido prestigio en el campo periodístico, sino que al estar asesorada por la RAE participa también de algún modo de su autoridad lingüística. Asimismo, una de las ventajas principales frente a la RAE es la continua actualización a través de noticias breves en su página web. En múltiples ocasiones recomienda usos, sin necesidad de emitir un dictamen definitivo o normativo. Sin embargo, como es lógico, tampoco la Fundación Fundéu brinda siempre propuestas satisfactorias ${ }^{2}$ respecto a topónimos y gentilicios.

Por último, deben mencionarse iniciativas privadas, es decir, propuestas recogidas en manuales de estilo o diccionarios de dudas de autores particulares. En esas obras, elaboradas normalmente por filólogos, suele figurar un número considerable de topónimos y gentilicios en español, con comentarios y sugerencias.

En todas las fuentes mencionadas se presentan elencos incompletos. Se trata normalmente de una selección realizada según los criterios de la institución o los criterios personales del autor. Son muchas, por tanto, las ausencias cuando se compraran las obras entre sí y contradictorias algunas informaciones.

\section{La Academia y el tratamiento de topónimos y gentilicios}

La atención que prestan las obras académicas al tema de los topónimos y gentilicios lógicamente difiere según la naturaleza de las mismas. Así el diccionario manual no recogerá topónimos, por tratarse de nombres propios, mientras que el Diccionario panhispánico de dudas, la Ortografía o El buen uso del español sí. Por su parte, la

\footnotetext{
${ }^{1}$ Muchos de estos manuales también se han publicado (en papel o en la red) y son asequibles a cualquier persona interesada.

${ }^{2}$ Curiosamente, la respuesta a una consulta a la Fundéu sobre el gentilicio de Bratislava fue: "Tiene información en la página de Wikipedia" (17/2/2016).
} 
Nueva Gramática no estudia los topónimos, pero se interesa por los gentilicios. Hacemos a continuación un breve recorrido por las obras académicas, que comentamos por orden cronológico.

El Diccionario panhispánico de dudas (2005, en adelante DPD), como el mismo título revela, se ocupa de cuestiones que presentan dudas en el usuario de la lengua. Por tanto, no trata el tema de manera sistemática sino que presta atención a aspectos puntuales; aquello que es obvio no forma parte de un diccionario de dudas. De los quince topónimos analizados aquí (Ámsterdam, Bratislava, Bucarest, Budapest, Copenhague, Estocolmo, Helsinki, La Valeta, Liubliana, Nicosia, Riga, Sofia, Tallin, Vilna y Zagreb), apenas se recogen seis. En ninguno de ellos se ofrece información sobre el gentilicio y el DPD tampoco cuenta con entradas aparte para ninguno ellos. La información que presenta es la siguiente ${ }^{1}$ :

Ámsterdam. Aunque el nombre neerlandés de la capital de los Países Bajos es Amsterdam — sin tilde y con pronunciación aguda: [amsterdám]—, en español está generalizada la pronunciación esdrújula [ámsterdam], por lo que este topónimo debe escribirse con tilde. En el habla esmerada debe evitarse la pronunciación [ásterdam].

Copenhague. Grafía asentada en español del nombre de la capital de Dinamarca. Se desaconseja, pues, la grafía simplificada Copenague. No debe usarse en español la forma inglesa Copenhagen ni el híbrido Copenhaguen.

La Valeta. Forma tradicional española del nombre de la capital de Malta. No debe usarse en español la grafía original La Valletta, y menos aún la semiadaptación La Valetta.

Liubliana. Forma adaptada a la ortografía y pronunciación españolas del nombre de la capital de Eslovenia. Se desaconseja el uso en español de la grafía eslovena Ljubljana. Tampoco debe usarse hoy el nombre alemán Laibach, con el que era conocida esta ciudad en otras épocas.

Tallin. Esta forma ha desplazado en el uso actual al nombre alemán Reval (en español, Revel), con el que fue conocida esta ciudad en épocas pasadas.

Vilna. Forma tradicional española del nombre de la capital de Lituania. No hay razones para sustituir el topónimo tradicional, aún vigente, por la forma lituana Vilnius.

Tabares afirma que el DPD desea "situar la norma en el ámbito del uso" (2014: 169), si bien, como veremos más abajo, no ha habido documentación suficiente sobre el uso real de los gentilicios.

La Nueva Gramática (2010: 532-539) dedica un capítulo (7.6.) a los "Sufijos característicos de los adjetivos de relación (I). Adjetivos gentilicios. Otros usos de los sufijos que los forman", donde principalmente se presta atención a los gentilicios, aunque también se hable de adjetivos derivados de antropónimos y de nombres comunes de lugar. De toda la información que se recoge en este apartado, deseamos destacar tres puntos. En primer lugar, la lista de sufijos con los que se forman normalmente los adjetivos gentilicios: -aco/-aca, -ano/-ana, -ata, -eco/-eca, -ego/-ega, -eno/-ena, -ense, -eño/-eña, -eo/-ea, -ero/-era, -és/-esa, -eta, -í, -ín/-ina, -ino/-ina, -ita, o/-a, -ol/-ola, -uno/-una. En segundo lugar, la afirmación de que "no es posible prever el sufijo que se elige para formar adjetivos gentilicios en cada nombre de lugar" (2010: 533). Por último, los académicos observan que unas veces el adjetivo gentilicio parte directamente sobre la base del topónimo en uso y en otras ocasiones parte de denominaciones latinas, griegas o de otro origen. Estas tres pautas nos servirán más

\footnotetext{
${ }^{1}$ Hemos omitido las citas periodísticas.
} 
adelante para proponer algunos gentilicios en español para las capitales de la Unión Europea que carecen de ellos.

La Ortografia de la RAE (2010: 640-647) contiene un capítulo sobre "La ortografía de los nombres propios", en cuyo tercer apartado se habla de los topónimos hispánicos y los topónimos extranjeros. Respecto a los últimos, distingue dos formas: los endónimos o nombre que dan los hablantes del lugar en la lengua autóctona (por ejemplo London) y los exónimos o nombre que una comunidad de hablantes da a un lugar que se encuentra fuera del ámbito de influencia de su lengua (por ejemplo Londres). Apunta la Academia que "el uso actual revela una clara predilección por la transferencia de la forma original. Este procedimiento se ha venido aplicando con nombres de lugar para los que no existía una denominación española tradicional (Aixen-Provence, Heidelberg, Montpellier o Plymouth) y es la fórmula habitual hoy para aquellos términos que irrumpen en nuestro repertorio toponímico" (2010: 645) ${ }^{1}$. Poco más adelante vuelve a insistir en que cuando "el topónimo no cuenta con un exónimo tradicional en español, el uso moderno se inclina por el mecanismo de la transferencia fidedigna de la forma original" (2010: 646). No obstante, la solución no resulta tan fácil como a primera vista parece, pues sabemos que muchas lenguas no poseen el alfabeto latino y su transcripción plantea serios problemas. En esos casos, la Academia aconseja que la grafía se asimile lo más posible a las pautas ortográficas y prosódicas del español. Esto, añadimos, es válido también para aquellas lenguas que emplean el alfabeto latino pero presentan combinaciones de letras ajenas a nuestro sistema lingüístico y requieren una adaptación, pues de otro modo resultan impronunciables; baste pensar en el topónimo checo Brno o en el polaco Bydgoszcz. La Ortografía recoge, además, como anexo una "Lista de países y capitales, con sus gentilicios", como anteriormente también lo ha hecho el DPD. Se trata de los países reconocidos por la ONU y sus capitales. No obstante, en esta lista faltan gran parte de los gentilicios.

El buen uso del español (2013) dedica un breve capítulo titulado a "Los gentilicios", donde se define el término ${ }^{2}$ y se comentan de forma compendiada aspectos ya tratados en la Ortografía y la Nueva Gramática. También recoge una lista de topónimos y gentilicios idéntica a la de la Ortografía y el DPD con cuatro leves diferencias: la introducción de Sudán del Sur, surdanés y Yuba (capitán de Sudán del Sur) y el topónimo Funafuti (capital de Tuvalu) ${ }^{3}$.

Por último, queda comentar la obra lexicográfica de la Academia, el Diccionario de la lengua española (2014). Si nos limitamos a nuestros gentilicios, confirmamos una vez más que tampoco aparecen en esta obra. Asombra, quizás, que al tratarse de quince capitales conocidas en Europa, muchas de ellas no tengan todavía un gentilicio. Si tomamos, por ejemplo, Sri Lanka (hasta 1972 Ceilán), vemos que desde que las autoridades del país deciden cambiar el topónimo hasta que los académicos españoles recogen esrilanqués en su diccionario por primera vez (DRAE-2014), han pasado

${ }^{1}$ En los ejemplos que proporciona la Academia, cabe preguntarse hasta qué punto en el caso de Heidelberg o Montpellier puede hablarse de una irrupción en el repertorio toponímico.

22 "Los gentilicios son adjetivos que denotan la nacionalidad o la procedencia geográfica de las personas. También hacen referencia a lo relacionado con dicha procedencia: politica americana, arte azteca. Proceden de los topónimos Nicaragua > nicaragüense, Santander > santanderino. Admiten usos adjetivos y sustantivos: las mujeres salvadoreñas/las salvadoreñas" (2013: 173).

${ }^{3}$ En la Ortografía figura: 'Fongafale: capital de Tuvalu, en el atolón de Funafuti'.

XLinguae Journal, Volume 9 Issue 3, June 2016, ISSN 1337-8384 
cuarenta y dos años. El DRAE-2014 recoge tres entradas ' : ceilanés ('natural de Ceilán, hoy Sri Lanka'), cingalés ${ }^{2}$ ('natural de Ceilán, hoy Sri Lanka, isla de Asia') y esrilanqués ('natural de Sri Lanka'). Curiosamente registra al mismo tiempo gentilicios modernos y antiguos para un mismo país ${ }^{3}$. Cabe plantearse si no es posible crear gentilicios para capitales europeas que cuentan con un topónimo más antiguo en español que Sri Lanka.

\section{Gentilicios de capitales de la Unión Europea}

En la actualidad son veintiocho las naciones que componen la Unión Europea. Trece de sus capitales cuentan en español con gentilicios reconocidos por la RAE y recogidos en el diccionario académico:

ateniense (Atenas), berlinés (Berlín), bruselense (Bruselas), dublinés (Dublín), lisboeta [lisbonense y lisbonés remiten a lisboeta] (Lisboa), londinense (Londres), luxemburgués (Luxemburgo), madrileño ${ }^{4}$ (Madrid), parisiense [parisino remite a parisiense] (París), praguense (Praga), romano (Roma), varsoviano (Varsovia), vienés (Viena)

Sobre las quince restantes capitales, la Real Academia Española no se ha pronunciado hasta la fecha y son también escasas las propuestas de los manuales y libros de estilo, pendientes casi siempre del veredicto de la Academia.

Es evidente que aunque existen muchas posibilidades a la hora de elegir un sufijo para formar un gentilicio y que, en principio, de Berlín podrían haberse derivado términos como berlinego, berlinense, berliniano, etc., también es verdad que por cuestiones fonéticas o semánticas el hablante discrimina automáticamente otras ${ }^{5}$ como berlinita (que en este caso recuerda más al sufijo diminutivo agregado a berlina, 'coche de caballos cerrado, comúnmente de dos asientos'), berlinol (que puede ser asociado a un medicamento o bebida), berlineño (algo más difícil de pronunciar que berlinense, por ejemplo). Si tomamos los topónimos Amsterdam, Bucarest y Budapest, observamos que hay combinaciones que no resultan posibles: amsterdameo, bucaresteta, budapesto, pues las terminaciones dan lugar con facilidad a la ridiculización. De modo que, aunque los académicos opinen que "no es posible prever el sufijo que se elige para formar adjetivos gentilicios en cada nombre de lugar" (Nueva Gramática, 2010: 533), se hace necesario matizar esta afirmación.

Además de las obras académicas, hemos consultado diccionarios de dudas (Fernández 2007, Instituto Cervantes 2013, Martínez de Sousa 2008, Seco 2011), diccionarios de topónimos y gentilicios (Faure 2004) y manuales de estilo (ABC 2001, Agencia EFE

${ }^{1}$ Sin embargo, las ediciones anteriores del DRAE no recogen ceilanés ni ceilandés (cfr. Nuevo tesoro lexicográfico y DRAE-2001).

${ }^{2}$ El DRAE-1992 ya define cingalés como 'perteneciente o relativo a esta isla de Asia, hoy Sri Lanka'.

3 La Fundación del Español Urgente recuerda que "a raíz del cambio de denominación, el gentilicio que se está utilizando es esrilanqués, aunque la Ortografía también sigue recogiendo las formas tradicionales ceilanés y ceilandés. En cambio, el gentilicio cingalés no se considera adecuado, pues alude solo a una de las etnias del país (no incluye a los tamiles, por ejemplo)". En: "Sri Lanka es el nombre de la antigua Ceilán”, 20-4-10, en la página web de Fundéu (consulta: 24/2/2016).

${ }^{4}$ El DRAE-2014 define también matritense como 'natural de Madrid'. No obstante, resulta extraña esta acepción, pues nadie dice "soy matritense".

5 También Tabares lo señala así al afirmar que la elección del sufijo "se debe a variadas razones de índole histórica, fónica o semántica, etc.” (2014: 170). 
2000, El País 2000, Martínez de Sousa 2012). Las informaciones sobre nuestros quince gentilicios son escasas e insuficientes:

Bratislava: capital de Eslovaquia, situada junto al Danubio y cerca de la frontera con Austria y Hungría. La forma antigua era Brecislava, pudiendo ser el primer elemento el antiguo eslavo *brec, 'orilla, ribera', y el segundo slav, 'eslavo', luego 'ribera de los eslavos', como alusión a una fundación eslava en ese lugar a orillas del Danubio. Los alemanes la llamaron en la Edad Media Brecislaburg de donde la forma alemana moderna Presburg. (Faure, 2004, s.v.)

Bratislava: nombre de la capital de Eslovaquia. El gentilicio correspondiente podría ser bratislavino/a, pero la Academia no recoge ninguno. (Fernández, 2007, s.v.)

El Libro de estilo de El País (2000) recoge Estonia, Lituania, Tallin, Vilna y Copenhague como entradas, pero solo ofrece gentilicios para los dos primeros (estonio y lituano). Una vez más se confirma, la poca atención que se presta a los gentilicios de algunas capitales europeas.

Por su parte, la Agencia EFE (2000) apunta:

Estonia: Para referirse a la capital de Estonia, debe utilizarse Reval y no Tallin, puesto que Reval es su nombre castellano. [...] El nombre en español de su capital es Reval y así debemos llamarla, aunque en las noticias actuales la veamos nombrada como Tallin, que es su nombre en la lengua local, el estonio, de la familia de las lenguas finesas. Asimismo, el hablante también duda sobre cuál es el gentilicio de este país. Es correcto tanto el uso de estonio,nia como el de estoniano,na: la cultura estonia/ la cultura estoniana. (s.v.)

Letonia: El gentilicio de Letonia es tanto letón como latvio, puesto que este país se conoce con el nombre de Letonia o Latvia. (s.v.)

Sin embargo, en ninguno de los tres casos ofrece el gentilicio de las capitales propuestas: Reval, Riga y Vilna. Seis años más tarde la misma Agencia EFE (2006: 15), al hablar de las quince repúblicas asociadas que formaban la URSS y que tras la caída del régimen comunista se convirtieron en países independientes, subraya la necesidad de castellanizar los topónimos y gentilicios propios de los nuevos países, que cuentan ahora con mayor relevancia en el plano político internacional. A raíz de eso propone:

Estonia: su gentilicio es estonio y su capital es Tallín (antiguamente, Reval. Gentilicio: tallinés). No es correcta la forma Tallinn.

Letonia: el gentilicio es letón. La capital es Riga (gentilicio: rigués).

Lituania: el gentilicio es lituano. Su capital es Vilna (Evítese la forma Vilnius. Gentilicio: vilnés).

Con el respaldo de la Real Academia, la Fundación Fundéu confirma sus propuestas:

La voz Vilna es la forma que recoge la Ortografia de la lengua española y, como indica el Diccionario panhispánico de dudas, no hay motivos para sustituir el topónimo tradicional español de esta capital por la forma lituana Vilnius ${ }^{1}$.

Se recomienda escribir Tallin y no Tallinn ni Tallín. Con este topónimo se denomina a la capital de la República de Estonia. Su grafía adecuada

${ }^{1}$ En la página web de Fundéu "Vilna, topónimo adecuado" (consulta: 24/2/2016). XLinguae Journal, Volume 9 Issue 3, June 2016, ISSN 1337-8384 
es Tallin según se recoge en la Ortografía de la lengua española. [...] Conviene además rechazar otras denominaciones como Reval, nombre alemán con el que antes se la conocía. ${ }^{1}$

En tercer lugar, hemos buscado páginas que ofrecen información sobre gentilicios. En concreto, hemos consultado Wikipedia (la página de presentación de las respectivas ciudades, la lista de gentilicios del mundo, la lista de gentilicios de Europa y las listas de personajes importantes según los gentilicios que propone esta fuente ${ }^{2}$ ) y blogs sobre la lengua, pues muchos de estos últimos suelen estar llevados por filólogos o aficionados y se puede presuponer cierta garantía de seriedad. Es indiscutible que no deseamos aquí atribuir a Wikipedia una autoridad lingüística de la que no goza, pero tampoco podemos negar que actualmente es una de las obras más consultadas en internet, de modo que no puede ser pasada por alto. Se trata de una información adicional que hemos tenido en cuenta. Comentamos brevemente algunas propuestas de Wikipedia que no se verifican. Esta enciclopedia digital propone, entre otros: aquineo para Bucarest; kobmendense, codano y hafnino para Copenhague; rigués para Riga; sardicense para Sofía y agramita y zagrebi para Zagreb. Sin embargo, no hemos encontrado ni una sola página donde aparezcan esas palabras. Tampoco los blogs mencionados resultan una fuente fiable ${ }^{3}$, pues a veces copian sus informaciones sin comprobar si son ciertas o no. Esto no significa que todos los gentilicios que se hallan ahí sean inexistentes. En cualquier caso, son fuentes que sirven de orientación y no puede olvidarse que ejercen una influencia considerable sobre los usuarios de internet.

\section{Posibles gentilicios para quince capitales europeas: propuestas de internet}

Recogemos a continuación en una tabla los topónimos de las quince capitales de la Unión Europea y sus posibles gentilicios, creados a partir de los sufijos que propone la Real Academia. Señalamos en negrita, aquellos para los que hemos encontrado ejemplos de uso en internet. No hemos tenido en cuenta, sin embargo, las citas que muestran desconocimiento o inseguridad, pues no puede afirmarse que sean

${ }^{1}$ En la página web de Fundéu "Tallin, y no Tallin ni Tallín" (consulta: 24/2/2016). La Fundéu no menciona Letonia (ni Riga ni rigués). El Diccionario panhispánico de dudas cuenta con una entrada para Letonia (no así para Estonia ni Lituania), donde tampoco se ve resuelta la cuestión del gentilicio de la capital: "Letonia. Forma tradicional española del nombre de este país de Europa, antigua república soviética: «Que regrese a Letonia o adonde sea que nació» (Donoso Elefantes [Chile 1995]). No debe usarse en español la forma vernácula Latvijas ni la inglesa Latvia. Su gentilicio es letón, que es también el nombre de su lengua oficial: «El nivel del fútbol letón tal vez es inferior al del maltés» (Abc [Esp.] 10.7.97). No debe usarse como gentilicio en español la forma latvio.” ¿Quizás por eso no se ha pronunciado al respecto la Fundéu?

${ }^{2}$ Sin embargo, no hemos recurrido a documentos de Wikipedia para atestiguar el uso de dichos gentilicios, pues es evidente que Wikipedia redacta sus artículos conforme a sus propias propuestas.

${ }^{3}$ Para no recargar el texto con extensos comentarios, nos limitamos a exponer un ejemplo. El blog sostiene que amstelodamense es gentilicio de Ámsterdam, bratislaviense de Bratislava y emonense de Liubliana. Ninguna de estas voces se recoge en el DRAE y tampoco aparecen en páginas de internet en español. 
propuestas. También hemos introducido todas las voces encontradas en el CORDE y CREA y nuevamente se ha repetido la sorpresa ${ }^{1}$. La suma de combinaciones arroja 19 gentilicios por cada topónimo de capital, es decir, un total de 285 posibles gentilicios. En caso de haber localizado otros formados con una raíz diferente, los añadimos aparte. Para no recargar demasiado el texto, presentamos las citas de internet a pie de página, una por para cada gentilicio encontrado; la dirección de la página web correspondiente aparece al final del artículo.

\begin{tabular}{|c|c|}
\hline Ámsterdam (Holanda) & 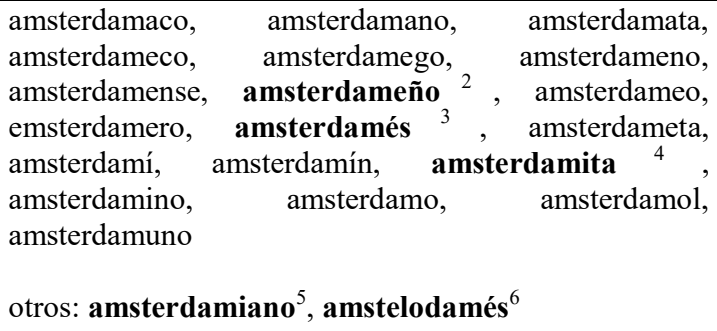 \\
\hline Bratislava (Eslovaquia) & $\begin{array}{l}\text { bratislavaco, bratislavano, bratislavata, bratislaveco, } \\
\text { bratislavego, bratislaveno, bratislavense } 7 \\
\text { bratislaveño }{ }^{8} \text {, bratislaveo, bratislavero, bratislavés, } \\
\text { bratislaveta, bratislaví, bratislavín, bratislavino, } \\
\text { bratislavita, bratislavo }{ }^{9} \text {, bratislavol, bratislavuno }\end{array}$ \\
\hline
\end{tabular}

${ }^{1}$ La única excepción ha sido la palabra budapestino, como 'perteneciente a Budapest', que recoge el CREA. Transcribimos la cita: "En la conferencia de Prensa de ayer no se nombró al cuarto integrante de la dirección, el secretario general, Karoly Grosz; se dijo sólo que toda la dirección está invitada, igual que los representantes de los demás partidos. En esta conferencia de Prensa, Johzsef Varga, por parte del Círculo Budapestino de Reforma, resaltó que en el POSH siempre estaban presentes las aspiraciones reformistas, pero nunca podían prevalecer"(ABC, 30/08/1989).

2 "Ahí, AHÍ, es en ese preciso instante cuando los habitantes de la ciudad comienzan a comprender que en esta vida hay que conocer y probar de todo, y por eso los amsterdameños son famosos por su tolerancia". [1]

3 "Todo esto se acompaña con deliciosos aperitivos y copas para ayudaros a mantener los niveles de energía bien altos. Bienvenido a la Noche de los Museos o, como los amsterdameses lo conocen, el «n8»»". [2]

4 "Los ciclistas amsterdamitas pusieron el grito en el cielo y levantaron el hacha de una guerra que acabaron ganando" (Diario de Navarra, 5/4/2013). [3]

5 "Con sus hileras de casa majestuosas y apacibles y los canales amsterdamianos (googlebooks: Ernesto Baltar: Ciudades en fragmento, p. 185) [4]

6 "Los Amstelodameses lo adoran. Cada vez que sale un rayito de sol van a pasar el día al parque". [5]

7 "En la metrópoli eslovaca sólo un 2\% de los habitantes utilizan la bicicleta como medio de transporte. En coche viajan diariamente un 23\% de los bratislavenses". [6]

8 "El idioma que cierto amigo mío asegura que se habla en la tierra de los bratislaveños". [7]

9 "En esta edición continua la apuesta por el Festival en las Islas que viajará por La Palma, La Gomera, El Hierro, Fuerteventura, Lanzarote y La Graciosa, llevando a XLinguae Journal, Volume 9 Issue 3, June 2016, ISSN 1337-8384 


\begin{tabular}{|c|c|}
\hline & otros: presburgués ${ }^{1}$ \\
\hline Bucarest (Rumanía) & $\begin{array}{l}\text { bucarestaco, bucarestano, bucarestata, } \begin{array}{l}\text { bucaresteco, } \\
\text { bucarestego, bucaresteno, bucarestense, bucaresteño }\end{array} \text {, } \\
\text { bucaresteo, bucarestero, bucarestés, bucaresteta, } \\
\text { bucarestí, bucarestín, bucarestino }{ }^{3} \text {, bucarestita, } \\
\text { bucaresto, bucarestol, bucarestuno }\end{array}$ \\
\hline Budapest (Hungría) & $\begin{array}{l}\text { budapestaco, budapestano, budapestata, budapesteco, } \\
\text { budapestego, budapesteno, budapestense, budapesteño, } \\
\text { budapesteo, budapestero, budapestés, budapesteta, } \\
\text { budapestí, budapestín, budapestino }{ }^{5} \text {, budapestita, } \\
\text { budapesto, budapestol, budapestuno } \\
\text { otros: aquincense }^{6} \text {, budapense }\end{array}$ \\
\hline Copenhague (Dinamarca) & $\begin{array}{lcc}\begin{array}{l}\text { copenhagaco, } \\
\text { copenhagueco, } \\
\text { copenhaguense }\end{array} & \begin{array}{c}\text { copenhagano, } \\
\text { copenhaguego, } \\
\text { copenhagueño, }\end{array} & \begin{array}{c}\text { copenhagata, } \\
\text { copenhagueno, } \\
\text { copenhagueo, }\end{array}\end{array}$ \\
\hline
\end{tabular}

cada isla cuatro agrupaciones de gran nivel, como los bratislavos Capella Istropolitana y los napolitanos I Truchini”. [8]

1 "El equipo presburgués lo cedió un par de campañas al RH Brno para que se foguease y retornó definitivamente en el año 1958". [9]

2 "Los bucaresteños les tratan muy bien y les dan comida, así que sin duda, esta ciudad es de los perros". [10]

3 "El choque Dinamo-Farul tuvo que ser interrumpido en el minuto seis, cuando los bucarestinos ganaban por tres a cero, después de una espectacular batalla campal entre jugadores, técnicos y representantes de los dos equipos". [11]

${ }^{4}$ Entre los ejemplos encontrados este resulta especialmente interesante por tratarse de un semanario del año 1919: "Respecto al acierto que han tenido los budapesteños para elegir como sitio de colocación de la horca el terreno frente al Ayuntamiento" (Semanario satírico, p. 327, Madrid, 1919). [12]

5 'La estatua llamada 'jugadores de bolos' por los budapestinos es un verdadero lugar de peregrinaje para muchos españoles que visitan el 'Parque Memento', donde se albergan las estatuas de la era comunista (1945-1989)". [13]

6 “A pesar de que en los medios se han visto imágenes de ciudadanos apoyando a los refugiados, aseguran que cuando se dirigían a llevar la compra a la estación los aquincenses les miraban mal sin entender por qué se solidarizaban con unas personas que estaban «ocupando nuestra estación»". [14]

7 "Budapenses durante la manifestación en apoyo a migrantes". [15]

8 “Los proyectos estimulan la economía, la innovación y la creación de empleo, y los copenhaguenses no albergan dudas de que las inversiones en medio ambiente y sostenibilidad se encuentran entre las iniciativas más importantes para asegurar el crecimiento futuro de la ciudad". [16] 


\begin{tabular}{|c|c|}
\hline & $\begin{array}{l}\text { copenhaguero, copenhagés, copenhagueta, copenhaguí, } \\
\text { copenhaguín, copenhaguino } 1, \text { copenhaguita, } \\
\text { copenhago, copenhagol, copenhaguno }\end{array}$ \\
\hline Estocolmo (Suecia) & $\begin{array}{l}\text { estocolmaco, estocolmano, estocolmata, estocolmeco, } \\
\text { estocolmego, estocolmeno, estocolmense }{ }_{2} \text {, } \\
\text { estocolmeño }^{3} \text {, estocolmeo, estocolmero, estocolmés }{ }^{4} \text {, } \\
\text { estocolmeta, estocolmí, estocolmín, estocolmino, } \\
\text { estocolmita }^{5} \text {, estocolmo, estocolmol, estocolmuno } \\
\text { otros: holmiense }^{6}\end{array}$ \\
\hline Helsinki (Finlandia) & $\begin{array}{l}\text { helsinkiaco, helsinkiano }{ }^{7} \text {, helsinkiata, helsinkieco, } \\
\text { helsinkiego, helsinkieno, helsinkiense }{ }^{8} \text {, helsinkieño, } \\
\text { helsinkieo, helsinkiero, helsinkiés, helsinkieta, helsinkí, } \\
\text { helsinkín, helsinkino, helsinkita, helsinkio, helsinkiol, } \\
\text { helsinkiuno } \\
\text { otros: } \\
\text { helsinguino }^{9} \text {, helsinkense }{ }^{10} \text {, }\end{array}$ \\
\hline
\end{tabular}

1 "Tras tomar unas cervezas en la animadísima calle de Nyhav -donde nos hemos integrado como los más consolidados copenhaguinos- y cenar nos fuimos al parque del Tívoli”. [17]

2 "Para los estocolmenses interesados en cultivar, un huerto en esta zona es como un pasaje a otro mundo con una subcultura y ambiente muy especiales". [18]

3 “Al equipo porteño le costó aterrizar tras el triunfo alcanzado ese día martes, ya que no se llevó la misma suerte al caer derrotado peloteando de visita ante el equipo de Solna, donde los estocolmeños se impusieron por la cuenta de 91-68". [19]

4 "Un $87 \%$ de los estocolmeses utilizan teléfono móvil y el $80 \%$ tienen acceso a internet en casa". [20]

5 “Abrían el concierto los suecos estocolmitas Structural Disorder. En fin, desde mi más profundo respeto a los músicos e incluso a los que piensan que lo son, no estaban a la altura ni de lejos". [21]

6 "Teniendo en cuenta que Estocolmo tiene una temperatura máxima de media que ronda los veintitrés grados en el mes de Julio, podríamos afirmar que actualmente los holmienses son los reyes de los looks de entretiempo". [22]

7 "Pero lo que realmente fascina a los helsinkianos es el diseño. Diseño de lo que sea: ropa, muebles, zapatos o interiores de peluquerías". [23]

8 "Globos y burbujas: Como cada Primero de Mayo, los helsinkienses cubren con sus mantas y sus cestas de picnic el gran parque de Kaivopuisto, junto a la costa de Helsinki. ¡Llegó la hora de festejar a lo grande!” [24]

9 "Finalmente, el rastro de Hietalahti, al final de la calle Bulevardi, casi en los astilleros, es donde los helsinguinos vacían en verano sus armarios y sus aparadores porque tanto diseño ya no les cabe". [25]

10 "En Helsinki podemos comer muy bien al mediodía las típicas comidas del país por precios que van desde los $6 €$ hasta $\operatorname{los} 25 €$ en los típicos restaurantes que frecuentan XLinguae Journal, Volume 9 Issue 3, June 2016, ISSN 1337-8384 


\begin{tabular}{|c|c|}
\hline & helsinkeño $^{1}$, helsinqueño $^{2}$ \\
\hline La Valeta (Malta) & $\begin{array}{l}\text { valetaco, valetano, valetata, valeteco, valetego, } \\
\text { valeteno, valetense, valeteño, valeteo, valetero, valetés, } \\
\text { valeteta, valetí, valetín, valetino, valetita, valeto, } \\
\text { valetol, valetuno }\end{array}$ \\
\hline Liubliana (Eslovenia) & $\begin{array}{l}\text { liublianaco, liublianano, liublianata, } \\
\text { liublianego, liublianeno, liublianense, } \\
\text { liublianeo, liublianero, liublianés }{ }^{3}, \\
\text { liublianí, liublianín, liublianino, liublianita } \\
\text { liublianol, liublianeta, } \\
\text { liubliano, }\end{array}$ \\
\hline Nicosia (Chipre) & $\begin{array}{l}\text { nicosiaco, nicosiano, nicosiata, nicosieco, nicosiego, } \\
\text { nicosieno, nicosiense, nicosieño, nicosieo, nicosiero, } \\
\text { nicosiés, nicosieta, nicosí, nicosín, nicosino, nicosiita, } \\
\text { nicosio, nicosiol, nicosiuno }\end{array}$ \\
\hline Riga (Letonia) & $\begin{array}{l}\text { rigaco, rigano, rigata, rigueco, riguego, rigueno, } \\
\text { riguense }^{5}, \text { rigueño }^{6} \text {, rigueo, riguero, rigués, rigueta, } \\
\text { riguí, riguín, riguino, riguita, rigo, rigol, riguno }\end{array}$ \\
\hline Sofía (Bulgaria) & $\begin{array}{l}\text { sofiaco, sofiano, sofiata, sofieco, sofiego, sofieno, } \\
\text { sofiense }^{7} \text {, sofieño, sofieo, sofiero, sofiés, sofieta, sofí,, } \\
\text { sofíin, sofino, sofiita, sofio, sofiol, sofiuno } \\
\text { otros: serdicense }^{8} \text {, sofiota }\end{array}$ \\
\hline
\end{tabular}

los helsinkenses donde sirven copiosas comidas llamadas "Lounas" propias de los trabajadores". [26]

1 "Helsinki también se queda ya en el recuerdo, tras un día completito allí, reno, frío y sauna era lo que necesitábamos para cumplir objetivos, y los cumplimos a medias, el reno probado en tapita, más no se podía, que estos Helsinkeños son un poco careros". [27]

2 "Y menos mal que a esas horas no hay helsinqueños por la calle que sino... también dirían eso de Go home!". [28]

3 "Entre tanto en cada esquina los liublianeses siguen conversando con los soldados de guardia, les bajan zumos y comidas, mientras llega el siguiente relevo en la furgoneta". [29]

4 "En la misma región se localizan, Vogel (Ukanc), el complejo Stari vrh (Zapreval) y, sobre todo, la favorita de los liublianitas estando como está a 20 kilómetros de la capital: Krvavec". [30]

5 "La semana pasada, junto al Monumento de la Libertad, uno de los pocos que sobrevivió a la devastación estalinista, miles de riguenses se citaron para escuchar a su presidente". [31]

6 "El 27 de octubre de 1884 los rigueños pudieron escuchar por primera vez las 12 campanas, pero la celebración de inauguración fue el 28 de octubre de 1884". [32]

7 "Las famosas spring falls, donde todos los "sofienses" llenan sus botellas con agua mineral....caliente!". [33]

8 "La diversidad tendrá que esperar a que la composición de los serdicenses cambie". [34] 


\begin{tabular}{|c|c|}
\hline Tallin (Estonia) & $\begin{array}{l}\text { tallinaco, tallinano }{ }^{2} \text {, tallinata, tallineco, tallinego, } \\
\text { tallineno, tallinense }{ }^{3} \text {, tallineño, tallineo, tallinero, } \\
\text { tallinés }{ }^{4} \text {, tallineta, talliní, tallinín, tallinino, tallinita, } \\
\text { tallino, tallinol, tallinuno }\end{array}$ \\
\hline Vilna (Lituania) & $\begin{array}{l}\text { vilnaco, vilnano, vilnata, vilneco, vilnego, vilneno, } \\
\text { vilnense } \mathbf{s}^{5} \text {, vilneño, vilneo, vilnero, vilnés, vilneta, vilní, } \\
\text { vilnín, vilnino, vilnita, vilno, vilnol, vilnuno }\end{array}$ \\
\hline Zagreb (Croacia) & $\begin{array}{l}\text { zagrebaco, zagrebano, zagrebata, zagrebeco, zagrebego, } \\
\text { zagrebeno, zagrebense }{ }^{6} \text {, zagrebeño }{ }^{7} \text {, zagrebeo, } \\
\text { zagrebero, zagrebés, zagrebeta, zagrebí, zagrebín, } \\
\text { zagrebino, zagrebita, zagrebo, zagrebol, zagrebuno }\end{array}$ \\
\hline
\end{tabular}

Antes de exponer y describir los resultados, es preciso comentar brevemente el sistema de búsquedas y las fuentes de internet. Al colocar en el buscador de internet cada uno de los 19 gentilicios posibles por capital, hemos comprobado que algunos no aparecen en absoluto; otros aparecen pero en páginas escritas en diversos idiomas; a veces el contenido de los link se repite ${ }^{8}$ y algunos han dejado de existir. De modo que el número de páginas y de los presumibles ejemplos de uso, resulta engañoso. Por tanto, es imprescindible comprobar en cada link la presencia del gentilicio. Respeto a las fuentes, abundan los blogs de viajes y las páginas relacionadas con el turismo, pero escasean los gentilicios en artículos periodísticos. Hemos dado preferencia a las citas de la prensa, tanto española como hispanoamericana. En caso de no encontrar los gentilicios en estas, hemos recurrido a páginas con información turística y a blogs, como última instancia. La prensa, a falta de directrices académicas y ausencia de indicaciones en sus propios manuales de estilo o sugerencias de la Fundéu, tiende a solucionar el problema a través de la combinación preposición 'de' más 'topónimo'.

1 "Si antaño era raro ver a los sofiotas montar bicicleta, en la actualidad las cosas han cambiado". [35]

2 “«Estonian Air volará de Múnich a Tallín a partir de esta primavera». ¿Qué bobada? No. Qué suerte para muniqueses y tallinanos”. [36]

3 "En el pozo que hay enfrente los atroces tallinenses medievales solían arrojar los gatos callejeros, esperando obtener a cambio prosperidad para el año venidero". [37]

4 "Desde principio de año, los tallineses tienen que presentar una nueva tarjeta verde al subir a los autobuses, los tranvías o los trolebuses, pero el trayecto es totalmente gratis". [38]

5 "A fines de octubre de 1974, los vilnenses quedaron sorprendidos, al percibir en la ciudad unos afiches fijados acerca del 1252 aniversario del fallecimiento del destacado florista sacerdote". [39]

6 "Sin embargo, esos incidentes se han atribuido luego a la participación de hinchas del club de fútbol zagrebense Dinamo". [40]

7 "El visitante igual puede pensar que se cruzará en la esquina o alguna plaza con algunos personajes del pasado zagrebeño". [41]

${ }^{8}$ En algunas páginas los textos son idénticos aunque la dirección de URL sea diferente y corresponda a periódicos diferentes. Como botón de muestra sirvan estos dos URL, el primero mexicano y el segundo chileno: [42] y [43]

XLinguae Journal, Volume 9 Issue 3, June 2016, ISSN 1337-8384 
También los foros contienen gentilicios, pero debido a su informalidad y a otras características, que no viene al caso comentar aquí, nos han parecido una fuente impropia para nuestro análisis ${ }^{1}$.

Comentarios a los resultados

A pesar de existir 285 posibles combinaciones para formar los gentilicios, solo se han confirmado 37. A estos hay que añadir cinco gentilicios que emplean otras raíces: amstelodamés, presburgués, aquincense, holmiense y serdence. Según la etimología, Amsterdam significa el "dique (dam) del Amstel"; en el gentilicio amstelodamés se ha añadido la vocal $o$ para facilitar la pronunciación. Presburgo proviene del alemán Pressburg, nombre con que se llamó la capital de Eslovaquia hasta 1918. En ese año, con la constitución de la República Checoslovaca cambió su nombre por Bratislava. A pesar de contar el español con topónimos como Estrasburgo, Luxemburgo, Edimburgo y sus respectivos gentilicios, apenas hemos encontrado un documento donde aparece presburgués. Sobre el origen de serdicense (de Serdica o Sardica), holmiense (de Holmia, nombre latino de Estocolmo) y aquincense (quizás de la antigua aldea de Aquincum, localizada dentro del área de la actual ciudad) existen diversas teorías.

La Valeta y Nicosia no cuentan con ningún gentilicio. Es discutible sobre qué raíz han de formarse los gentilicios de Nicosia, si sobre nicos- o sobre nicosi-. En teoría, son defendibles ambas posibilidades. ¿Por qué nicosieño y no nicoseño o por qué nicoso y no nicosio? Lo mismo puede aplicarse a La Valeta. Si Amsterdam admite -iano y surge así un nuevo sufijo gentilicio, ¿qué impide añadir a Valeta esa misma terminación y formar valetiano, en lugar de valetano?

La mayoría de los topónimos estudiados nos ofrecen entre dos y tres gentilicios; excepcionalmente cinco (como es el caso de Ámsterdam, Bratislava, Estocolmo y Helsinki). De estos dos o tres, si se atiende a la frecuencia de uso, se percibe una clara preferencia por uno de ellos.

Generalmente, cuando los topónimos terminan en consonante, el sufijo se añade directamente al topónimo (tallinés, zagrebense). Budapest presenta un caso aparte, pues la raíz, sin que sepamos por qué, se reduce a budap- en budapense. Cosa que no sucede con Bucarest. Si el topónimo termina en vocal, se suele omitir para añadir el sufijo (bratislavense, rigués). Si bien no queda del todo resuelto cuando la vocal es una $i$ o existe diptongo o hiato, como es el caso de Helsinki, Nicosia y Sofía.

Entre los sufijos empleados, se registran dos que no menciona la Nueva Gramática iano (amsterdamiano) y -ota (sofiota $)^{2}$. En orden estadístico, los sufijos que más se repiten en los gentilicios de las quince capitales de la Unión Europea son -ense (nueve veces: bratislavense, budapense, copenhaguense, estocolmense, helsinkiense, riguense, sofiense, vilnense, zagrebense), -eño (siete veces: amsterdameño, bratislaveño, bucaresteño, estocolmeño, helsinkeño, rigueño, zagrebeño), -és e -ino (cinco veces: amterdamés, estocolmés, liublianés, tallinés, vilnés y bucarestino,

\footnotetext{
${ }^{1}$ También hemos prescindido de blogs donde se plantean dudas sobre el gentilicio, pues propiamente no pueden considerarse propuestas.

${ }^{2}$ Sufijos que también se emplean en marciano ('supuesto habitante del planeta Marte') y chipriota; en este último caso con una $i$ añadida.
} 
budapestino, copenhaguino, estocolmino, helsinguino),-ita (tres veces: amsterdamita, estocolmita, liublianita,), -ano (dos veces: helsinkiano, tallinano).

El topónimo que más gentilicios admite es Helsinki. En los gentilicios de Helsinki observamos varios alogentilicios que se producen en la alternancia de la $k$ y la $q$ y en la sonorización de la $k$; si bien predominan las formas con consonante sorda. Así se registran: helsinkeño junto a helsinqueño; helsinguense y helsinkense. Otra duda que se presenta es la $i$ final de Helsinki, ¿debe omitirse? Algunas propuestas la admiten (helsinkiense) mientras que otras la eliminan (helsinkense). En cualquier caso, habría que decidirse por una de las tres posibilidades y aclarar qué sucede con la $i$. Si conservamos el sonido velar y probamos con el sufijo -ano, se producen cinco gentilicios: helsinkiano, helsinquiano, helsinguiano, helsincano, helsingano (de los cuales solo se documenta el primero).

Por último, señalamos cuales son los gentilicios con un índice de frecuencia más alto. Para Ámsterdam se consolida amsterdamés, que aparece en gran cantidad de páginas web de todo tipo. Para Bratislava bratislavense, seguido de bratislavo; para Bucarest el único gentilicio que realmente funciona es bucarestino. De Budapest budapestino, de Copenhaguen copenhaguense, de Estocolmo el gentilicio más usado es holmiense seguido de estolcomense. Para Liubliana liublianense, Riga riguense, Sofia sofiota, Tallin tallinés, Vilna vilnés y Zagreb zagrebense. Los demás gentilicios se recogen solamente una vez (bucaresteño aparece en un único blog y lo mismo sucede con bratislavero y tallinano); la presencia de otros alcanza entre dos y diez ejemplos de uso, de modo que no son cifras representativas.

\section{Conclusiones}

De todo lo expuesto hasta aquí deseamos hacer tres consideraciones, que llevan necesariamente a tres propuestas concretas.

La primera se refiere al caos que reina en cuestión de gentilicios, pues al no existir una norma surge la variedad. Cada cual propone lo que considera correcto, según criterios personales de gusto y haciendo uso de su competencia lingüística. El resultado es una proliferación innecesaria de variantes ${ }^{1}$. Por tanto, urge poner orden y crear una norma, pues no se trata de simples ciudades o pueblos europeos más o menos conocidos, sino de las capitales de quince países miembros de la Unión Europea, que conviene que tengan un gentilicio estandarizado, reconocido y uniforme en español. $\mathrm{Si}$ se ha conseguido formar un gentilicio como esrilanqués (ni la dificultad fonética ni la relativa modernidad del topónimo lo han impedido), con más razón se puede defender la creación de gentilicios para Bratislava, Estocolmo o Vilna. $\mathrm{Si}$ algunas capitales pueden plantear dificultad fonética (por ejemplo Ámsterdam, Helsinki o Liubliana), no quiere decir que este obstáculo sea insalvable y prueba de ello son las propuestas que existen y circulan en internet. Los usuarios emplean ya algunos gentilicios, de entre los que es posible escoger algunos.

\footnotetext{
${ }^{1}$ Martín (2013) se refiere a los dobletes de los topónimos presentes en el DPD y reitera que "el ideal de una lista toponímica interinstitucional es que esos dobletes se reduzcan, de manera que los topónimos aparezcan en los documentos oficiales con una única forma armonizada". Esto también habría que aplicarlo a los gentilicios y sus múltiples alogentilicios.
}

XLinguae Journal, Volume 9 Issue 3, June 2016, ISSN 1337-8384 
Sobre el problema de los topónimos extranjeros la discusión acusa dos claras tendencias, por un lado la que se inclina por el topónimo endónimo y, por otro, la que exige la adaptación. Renunciar a los topónimos exónimos a favor de los endónimos, como propone, por ejemplo, la Conferencia de las Naciones Unidas sobre las Normalización de Nombres Geográficos (United Nations Conference on the Standardization of Geographical Names) supone, en muchos casos, complicar aún más las cosas para la formación de los gentilicios en español.

Nuestra segunda propuesta está relacionada con el criterio para escoger entre los gentilicios existentes. Consideramos que el criterio debería ser el de frecuencia. Es imposible ignorar la fuerza arrolladora de los medios de comunicación (incluida internet), demasiado fuerte como para contenerla y prueba de ello es que en muchos casos ha impuesto el uso a pesar de las prescripciones académicas. Así se han dejado de usar Brema, Angora Mastrique y Revel a favor de Bremen, Ankara, Maastricht y Tallin. La Academia ha tenido que ceder, como es lógico, a favor del uso real. Excepto Nicosia y La Valeta, los restante trece topónimos cuentan en internet con diversas formas gentilicias e incluso para estos topónimos se puede formar fácilmente un gentilicio. Los más frecuentes los hemos mencionado arriba al exponer los resultados de la búsqueda: amsterdamés, bratislavense, bucarestino, budapestino, copenhaguense, helsinkiense, holmiense (o estolcomense, si se desease conservar el topónimo actual), liublianense, riguense, sofiota, tallinés, vilnés y zagrebense.

No necesitamos cinco gentilicios por capital. Si el primer diccionario de la Institución, el Diccionario de autoridades, se basaba en el buen uso de la lengua de los grandes literatos, "la autoridades literarias", y en el siglo XX se han considerado también las fuentes periodísticas impresas y digitalizadas -tanto en la obra lexicográfica clásica de la Academia como en los corpus CORDE y CREA-, en el siglo XXI deberían tenerse en cuenta otros materiales, que sin duda reflejan también el uso de la lengua. La creación de gentilicios nuevos, la normalización o estandarización de los que están en uso, sería muy beneficiosa para todos y se evitarían confusiones. Basta con prestar atención a las propuestas existentes. Tabares, refiriéndose al Diccionario panhispánico de dudas -y puede extenderse a toda la labor de la Academia-, apunta con acierto:

En las advertencias «previas» se establece que se recogerán las formas gentilicias recomendadas cuando estas existan. Este criterio de la «existencia» resulta inquietante $[. .$.$] ¿Se refiere a cuando estas formas se$ registran en el DRAE, cuando se encuentran en las bases de datos académicas? Y en este último supuesto, ¿a partir de cuándo o en qué circunstancias se puede considerar que los testimonios son suficientes y necesarios para que esa forma se consolide como «existente»? por lo demás, hubiera sido una oportunidad de oro para ofrecer una solución a la supuesta «inexistencia» proponiendo nuevos gentilicios (2014: 177)

Esta observación, empalma con nuestra tercera propuesta. La Real Academia Española, en colaboración con la Asociación de Academias de la Lengua Española, ostenta una reconocida autoridad lingüística como institución reguladora de la lengua, y debería pronunciarse con claridad sobre la corrección de algunas formas en circulación y, a su vez, ofrecer una propuesta para aquellos gentilicios que aún no existen. De esta manera, resuelve dudas y fortalece la unidad de la lengua. La situación actual es que cada usuario hace uso de su imaginación y los manuales de estilo no terminan de dar respuesta satisfactoria a la cuestión de los gentilicios. Como señala Sánchez García (2009), "los libros de estilo surgieron con la intención de dar ideas generales que sirvieran de orientación para armonizar el estilo de redacción, pero casi desde el primer momento pasaron a ser un conjunto de normas internas para el manejo apropiado de la lengua en un determinado medio de comunicación, de cumplimiento obligado para sus redactores" (2009); de modo que tampoco llegan a un 
público amplio. Por otro lado, cuando se comparan unos manuales con otros, se descubren ciertas disonancias o propuestas contradictorias. De ahí que numerosos autores hablen de la "necesidad de buscar una uniformidad en la adopción de determinados usos lingüísticos" (García Sánchez 2009) y critiquen la falta de criterio unificado.

En resumen, urge disponer de una lista de topónimos y gentilicios única y lo más completa posible, que sea elaborada por la RAE y la ASELE, autoridades lingüísticas reconocidas en el mundo hispánico ${ }^{1}$. Esta lista, además, como propone González (1995) debe ser actualizada y actualizable y basarse tanto en criterios de uso como de hispanización; de este modo se registra la implantación y evita la vacilación ${ }^{2}$. Esta medida favorecería a todos los usuarios de la lengua.

\section{Referencias de las páginas web}

[1] http://inciclopedia.wikia.com/wiki/\%C3\%81msterdam

[2] http://www.iamsterdam.com/es/visitar/actualidad/festivales/overview-culturalfestivals/la-noche-de-los-museos

[3] http://www.coavna.com/wp-content/uploads/en-los-

medios/DN542013\%282\%29.pdf

[4]https://books.google.sk/books?id=6gOuBgAAQBAJ\&pg=PA199\&dq=Ciudades+e $\mathrm{n}+$ fragmento\&hl $=$ sk\&sa $=X \& v e d=0$ ahUKEwjE2tC-

rZ_LAhUDYZoKHYIKAO8Q6AEIGjAA\#v=onepage \&q=Ciudades $\% 20$ en $\% 20$ fragm ento\&f=false

[5] http://www.dooyoo.es/europa/vondelpark-amsterdam/1215657/

[6] http://www.rtvs.sk/televizia/archiv/7770/60122v

[7] http://hablandoenbratislavo.blogspot.sk/

[8] http://www.laprovincia.es/cultura/2014/07/16/hora-orquestas-

pequenas/620808.html

[9] http://sinborceguiesnohayfutbol.blogspot.sk/2014/09/janpopluhar-el-mejor-

futbolista.html

[10] http://martaenrumania.blogspot.sk/2008/07/el-tamao-importa.html

[11]http://internacional.elpais.com/internacional/2013/12/11/actualidad/1386764103_

324876.html

[12] hemerotecadigital.bne.es

[13] http://www.terra.com.mx/articulo.aspx?articuloId=588636

${ }^{1}$ Entre otros, Martín (2013) defiende que la lista sea realizada por una autoridad competente, es decir las Academias de la lengua, por su prestigio entre los hispanohablantes y porque sus recomendaciones son seguidas por instituciones privadas con gran influencia en medios de comunicación, tales como la Fundéu. Este autor propone formar una célula toponímica en el seno de la RAE que cumpla con dicho objetivo.

${ }^{2}$ También Vidal (2006) propone disponer de una lista de Estados y territorios única para todas las instituciones europeas; aunque en realidad esa lista la deberían adaptar todas las instituciones hispanohablantes, se encuentren donde se encuentren, y debería incluir también los gentilicios. Años más tarde, también Martín (2013) expresa la misma idea: "sería deseable que los servicios de traducción de las instituciones europeas dispusieran de unos criterios de adaptación de topónimos precisos y coherentes que contribuyeran a evitar en lo posible las vacilaciones continuas y los atentados a la lengua". Y repetimos, no se trata solo de los traductores sino de beneficiar a cualquier usuario. 
[14] http://www.eldiario.es/canariasahora/internacional/gente-mira-llevarle-aguarefugiados_0_427657534.html

[15] http://www.elnuevodiario.com.ni/galerias/2900/

[16]http://www.revistaambienta.es/WebAmbienta/marm/Dinamicas/secciones/articulo s/Copenhague.htm

[17] http://marcopoleandoporeuropa.blogspot.sk/2013/07/con-buen-tiempo-porcopenhague.html

[18] http://www.visitsweden.com/suecia/Regiones-y-ciudades/Estocolmo/Naturalezaen-Estocolmo/Los-huertos-de-Tanto/

[19] http://www.prensanorrkoping.com/?p=3008

[20]http://www.edicionesespeciales.elmercurio.com/destacadas/detalle/index.asp?idn oticia $=0106062005021 \mathrm{X} 0100019 \&$ idcuerpo

[21] https://filotecnologa.wordpress.com/category/musica/

[22] http://lookandfashion.hola.com/jailacleprivee/20140901/street-style-estocolmo/

[23] http://www.sevillaactualidad.com/opinion/tribuna-libre/8122-solo-se-trata-dediseno

[24] http://finland.fi/es/vida-y-sociedad/vappu-finlandia-y-los-colores-del-primero-demayo/

[25]

http:/elviajero.elpais.com/elviajero/2014/07/11/actualidad/1405088758_878834.html

[26] http://www.logitravel.com/guias-de-viajes/gastronomia-helsinki-587_2.html

[27] http://nosvamosaleurobasket.blogspot.sk/2011/09/partida-kaunas.html

[28] https://peramoralart.wordpress.com/tag/finlandia/

[29]http://hemeroteca.abc.es/nav/Navigate.exe/hemeroteca/madrid/abc/1991/06/30/03 9.html

[30] http://www.hola.com/viajes/2013112768326/eslovenia-estaciones-esquiinvierno-3013/

[31] http://diariovasco.com/culturas/201412/07/riga-situo-mapas-201412071312.html

[32] http://rigaturistica.blogspot.sk/2012/09/catedral-ortodoxa-del-nacimiento-de.html

[33] http://dosgordoseuropeos.blogspot.sk/2008/06/bulgaria-sofia.html

[34] http://crestomatia.net/2014/11/18/anhelo-estival/

[35] http://bnr.bg/es/post/100210407/descubrir-a-sofia-en-verano

[36] http://viajar.elperiodico.com/en-la-revista/abrir-romper-ciudades-por-jesustorbado

[37] http://viajesmorrocotudos.blogspot.sk/2011/06/rataskaevu-14.html

[38] http://www.montevideo.com.uy/auc.aspx?191027,1,1149

[39] http://www.lkbkronika.lt/index.php/es/cronica-no-14/708-noticias-de-las-

diocesis.html

[40] http://www.lostiempos.com/diario/actualidad/internaciona/20110302/mas-de-

5000-personas-piden-en-zagreb-la-dimision-del-gobierno_115416_228822.html

[41] http://business.croatia.hr/Documents/838/Hoteles-familiares-y-hotelespequenos.pdf

[42] http://www.legiscomex.com/BancoConocimiento/C/croacia-accede-ue-mar-1113-17not/croacia-accede-ue-mar-11-13-17not.asp?CodSeccion=

[43] _http://economia.terra.cl/croacia-y-eslovenia-firman-acuerdo-que-desbloquea-elacceso-croata-a-la-ue,4768606066d72410VgnCLD200000bbcceb0aRCRD.html

\section{Bibliographic references}

AGENCIA EFE. 2000. Manual de español urgente. Madrid: SM. ISBN 978-84-3762142-5.

AGENCIA EFE. 2006. Topónimos y gentilicios de las antiguas repúblicas socialistas soviéticas. En: Revista Donde dice... año 1, n. 3, abril-junio, p. 15. 
ALVAR EZQUERRA, M. 2004. Nuevo diccionario de voces de uso actual. Madrid: Arco Libros. ISBN 978-84-7635-556-5.

BEZOS LÓPEZ, J. 2011. Toponimia en el Panhispánico. La falta de criterio de la RAE en el Diccionario panhispánico de dudas. En: http://textipografia.com/dpdtopo.html

EL PAÍS. 2002. Libro de estilo de El País. Madrid: Santillana. ISBN 978-84-0309223-5.

FAURE SABATER, R. 2004. Diccionario de nombres geográficos y étnicos del mundo. Madrid: Espasa. ISBN 978-84-670-1663-5.

FERNÁNDEZ FERNÁNDEZ, A. 2007. Diccionario de dudas A-H, I-Z (dos tomos). Oviedo: Ediciones Nobel. ISBN 978-84-8317-635-1.

FERRÉS, D. - RODRÍGUEZ, H. 2015. Evaluating geographical knowledge reranking, linguistic processing and query expansion techniques for geographical information retrieval. En: Lecture Notes in Computer Science, n. 9309, pp. 311-323. ISSN 0302-9743.

FUNDÉU. Fundación del Español Urgente: varias entradas http://www.fundeu.es/dudas/

GARCÍA SÁNCHEZ, J. J. 2009. La toponimia en los medios de comunicación españoles en castellano con especial atención a sus libros de estilo. En: http://www.fomento.gob.es/NR/rdonlyres/C49D4959-0250-4058-9746-

009AD56617ED/71711/topomediosespa\%C3\%B1oles.pdf

GARCÍA PADRÓN, D./MORERA, M. 2015. Gentilicios y lexicografía. En: Onomázein, n. 31, pp. 81-98. ISSN 0718-5758.

GÓMEZ FONT, A. 1998. Los libros de estilo de los medios de comunicación en español: necesidad de un acuerdo. https://pendientedemigracion.ucm.es/info/especulo/ele/g_font.html

GOMEZ TORREGO, L. 2000. Ortografía de uso del español actual. Madrid: SM. ISBN 978-84-675-1568-8.

GONZÁLEZ, A.D.F. 2013. El nombre de los otros: sociolingüística gentilicia en el Último Patriarca de Najat El-Hachmi. En: Tonos digital. Revista electrónica de estudios filológicos, n. 25, pp. 1-37. ISSN 1577-6921.

GONZÁLEZ, L. 1995. Algunas propuestas generales para una lista de nombres de países. En: Punto y coma. Boletín de los traductores españoles de las instituciones de la Unión europea, n. 34. ISSN 1830-5415. En: http://ec.europa.eu/translation/bulletins/puntoycoma/34/pyc344.htm

GYÖRFFY, E. 2013. The place of slang toponyms in the toponymic system. En: Acta Onomastica, n. 54, pp. 80-86. ISSN 1211-4413.

INSTITUTO CERVANTES. 2013. Las 500 dudas más frecuentes del español. Madrid: Instituto Cervantes-Espasa. ISBN 978-84-670-3981-8.

MARTÍN RODRÍGUEZ, M. 1995. Una propuesta de traducción de topónimos de países. En: Punto y coma. Boletín de los traductores españoles de las instituciones de la Unión europea, n. 34. ISSN 1830-5415. En: http://ec.europa.eu/translation/bulletins/puntoycoma/34/pyc346.htm

MARTÍN RODRÍGUEZ, M. 2013. Toponimia extranjera en las instituciones europeas y la nueva Ortografía: informe de unas consultas. En: Punto y coma. Boletín de los traductores españoles de las instituciones de la Unión europea, n. 131. ISSN 1830-5415.

En: http://ec.europa.eu/translation/bulletins/puntoycoma/131/pyc1316_es.htm

MARTÍNEZ DE SOUSA, J. 2012. Manual de estilo de la lengua española (MELE 3). Gijón: Ediciones Trea. ISBN 978-84-9704-606-0. 
MARTÍNEZ DE SOUSA, J. 2008. Diccionario de usos y dudas del español actual (DUDEA). Gijón: Trea. ISBN 978-84-9704-371-7.

MIHALJEVIĆ, A. 2014. Non-Slavic anthroponyms on Latin epigraphic monuments from the first centuries of Croatian literacy. En: Folia Onomastica Croatica, n. 23, pp. 159-184. ISSN 1330-0695.

REAL ACADEMIA ESPAÑOLA Y ASOCIACION DE ACADEMIAS DE LA LENGUA ESPAÑOLA. 2010. Ortografía de la lengua española. Madrid: Espasa. ISBN 978-84-670-0500-4.

REAL ACADEMIA ESPAÑOLA Y ASOCIACION DE ACADEMIAS DE LA LENGUA ESPAÑOLA. 2005. Diccionario panhispánico de dudas. Madrid: Santillana. ISBN 978-84-294-0623-8.

REAL ACADEMIA ESPAÑOLA. 2014. Diccionario de la lengua española. Madrid: Espasa. ISBN 978-84-670-4189-7.

REAL ACADEMIA ESPAÑOLA. 2009-2011. Nueva gramática de la lengua española. Madrid: Espasa. ISBN 978-84-670-3321-2.

REAL ACADEMIA ESPAÑOLA. 2013. El buen uso del español. Madrid: Espasa. ISBN 978-84-670-3993-1.

SECO, M. 2011. Nuevo diccionario de dudas y dificultades de la lengua española. Madrid: Espasa. ISBN 978-84-670-3787-6.

SECO, M. - ANDRÉS, O. - RAMOS, G. 1999. Diccionario del español actual (DEA), 2 vol. Madrid: Aguilar. ISBN 978-84-294-6472-6.

TABARES PLASENCIA, E. 2014. El tratamiento de los gentilicios en el Diccionario panhispánico de dudas. En: Revista de Lexicografía, n. 20, pp. 167-186. ISSN 11344539.

MINISTERIO DE FOMENTO. Toponimia y nomenclátores geográficos. En: http://www.ign.es/ign/layoutIn/actividadesToponimia.do

UNIÓN EUROPEA. Oficina de Publicaciones de la Unión Europea. 2015. Libro de estilo interinstitucional. Anexo A5: Lista de Estados, territorios y monedas. En: http://publications.europa.eu/code/es/es-5000500.htm

VIDAL, M. 2006. Traducir (o no) los topónimos. En: Punto y coma. Boletín de los traductores españoles de las instituciones de la Unión europea, n. 100. ISSN 18305415. En: http://ec.europa.eu/translation/bulletins/puntoycoma/100/pyc10022 es.htm VIGARA, A. 2001. Libro de estilo de ABC. Barcelona: Ariel. ISBN 84-344-8245-2. WEINMAN, J. 2013. Toponym recognition in historical maps by gazetteer alignment. En: Proceedings of the International Conference on Document Analysis and Recognition, ICDAR, pp. 1044-1048. ISSN 1520-5363.

Words: 6378

Characters: 46174 (25, 65 standard pages)

Dr. Beatriz Gómez-Pablos, PhD.

Comenius University in Bratislava

Faculty of Education

Department of Romance languagues and literatures

Šoltésovej 4,

81108 Bratislava, Slovakia

gomezpablos@fedu.uniba.sk 